\title{
Produção e composição química da uva de videiras Cabernet Sauvignon submetidas à adubação nitrogenada
}

\author{
Grapes yield and chemistry composition in Cabernet Sauvignon grapevine with nitrogen fertilization
}

\author{
Gustavo Brunetto ${ }^{\mathrm{I}}$ Carlos Alberto CerettaII João KaminskiII George Wellington de Melo ${ }^{\text {III }}$ \\ Eduardo Girotto ${ }^{\text {II }}$ Eder Efrain Trentin ${ }^{\text {II }}$ Cledimar Rogério Lourenzi ${ }^{\text {II }}$ \\ Renan Costa Beber Vieira ${ }^{\text {IV }}$ Luciano Colpo Gatiboni ${ }^{V}$
}

A adubação nitrogenada em videiras é realizada para suprir a demanda da planta pelo nutriente. Porém, o nitrogênio $(N)$ deve ser usado com prudência porque afeta a produção e a composição química da uva e do seu mosto, nem sempre na mesma direção. O trabalho objetivou avaliar o efeito da aplicação de $N$ na produção de uva, em seus componentes e na composição química do seu mosto. $O$ experimento foi desenvolvido na safra 2004/05, em vinhedo de viníferas Cabernet Sauvignon, na área experimental da Embrapa Uva e Vinho, em Bento Gonçalves, Rio Grande do Sul (RS), sobre NEOSSOLO LITÓLICO. Os tratamentos foram testemunha, 15, 30, 45 e $60 \mathrm{~kg} \mathrm{ha}^{-1}$ de $\mathrm{N}$ aplicados durante o ciclo vegetativo e produtivo. Na maturação, a uva foi colhida, e o seguintes variáveis foram avaliadas: a produção por planta e por hectare, o comprimento e a largura de cachos e a massa de 100 bagas. Foram coletadas bagas de uva, sendo uma parte amassada, e no mosto foram determinados os sólidos solúveis totais, o pH, a acidez total, o ácido tartárico e málico, os polifenóis totais, as antocianinas e o $N$ amoniacal. As bagas restantes foram trituradas, e foi analisado o total de $N, P, K, C a$ e $\mathrm{Mg}$. Os resultados mostraram que a produção de uva de viníferas Cabernet Sauvignon em solos com teores médios de matéria orgânica é máxima com a aplicação de doses de 15 e $30 \mathrm{~kg} \mathrm{ha}^{-1}$ de $\mathrm{N}$. A aplicação de $\mathrm{N}$ aumenta os teores de $N$ amoniacal no mosto, mas diminui as antocianinas, e aumenta a porcentagem de $K$ nas bagas, o que interfere na cor dos vinhos tintos e na formação de precipitados.

Palavras-chave: Vitis vinifera, nitrogênio, componentes de produção, mosto.

\section{ABSTRACT}

Fertilization of grapevines with $N$ is generally accomplished to supply the demand for $N$. However $N$ should be used with prudence because affect the yield and chemical composition of the grape and your must. The experiment was carried out in 2004/05, to evaluate the effect of $N$ fertilization on the grape yield and on the chemical composition of the grape and must of Cabernet Sauvignon grapevines, at Udorthent soil at Southern Brazil, Bento Gonçalves city. The treatments were control, 15, 30, 45 and $60 \mathrm{~kg} \mathrm{ha}^{-1} \mathrm{~N}$, added during the vegetative and productive period. In the maturation, the grape was collected. Grape yield by plant and by hectare, length and width of bunches were evaluated and 100 berries were weighted. Berries were collected and a part of them was used to evaluate soluble solids in the must, $\mathrm{pH}$, total acidity, tartaric acid, malic acid, total phenols, anthocyanins and $N$ ammonia. The remaining berries were triturated and used to evaluated total $N, P, K, C a$ and $M g$. The results showed that the yield of Cabernet Sauvignon grapevines in soils with medium content of organic matter is maximum with the fertilization of 15 and $30 \mathrm{~kg} \mathrm{ha}^{-1} \mathrm{~N}$. The $\mathrm{N}$ fertilization increased the values of ammonia in the must and potassium percentage in the berry, but decreased the values of anthocyanins, what interferes the color of red wines and the formation of precipitate

Key words: Vitis vinifera, nitrogen, yield components, must.

\section{INTRODUÇÃO}

Os vinhedos de viníferas tintas na Serra Gaúcha do Rio Grande do Sul (RS), que é a maior região

IDepartamento de Engenharia de Biossistemas, Universidade Federal de São João Del Rei (UFSJ), Campus Dom Bosco, Praça Dom Helvécio, 74, Bairro Fábricas, 36301-160, São João Del Rei, MG, Brasil. E-mail: brunetto.gustavo@gmail.com. Autor para correspondência.

IIPrograma de Pós-graduação em Ciência do Solo, Universidade Federal de Santa Maria (UFSM), Santa Maria, RS, Brasil.

IIIEmbrapa Uva e Vinho, Bento Gonçalves, RS, Brasil.

IVPrograma de Pós-graduação em Ciência do Solo, Universidade Federal do Rio Grande do Sul (UFRGS), Porto Alegre, RS, Brasil.

${ }^{v}$ Departamento de Solos e Recursos Naturais, Universidade do Estado de Santa Catarina (UDESC), Lages, SC, Brasil. 
vitivinícola do Brasil, são formados predominantemente por Cabernet Sauvignon. Eles, em geral, estão localizados em solos com médio ou baixo teor de matéria orgânica, mas com intenso crescimento de espécies que co-habitam os vinhedos (BRUNETTO, 2004; BRUNETTO et al., 2006a; BRUNETTO et al., 2006b; BRUNETTO, 2008a). Com isso, há deposição de resíduos orgânicos na superfície do solo durante o ano todo, cuja condição climática-ambiental e a composição bioquímica determinam as taxas de mineralização que controlam a ciclagem de nutrientes nesse sistema (TRINSOUTROT et al., 2000; AGEHARA \& WARNCKE, 2005). Essa ciclagem não significa input de nutrientes, mas transferência para as zonas de absorção radicular, havendo necessidade de complementar a demanda fisiológica da planta pela adição de fertilizantes durante o ciclo vegetativo e produtivo, quando as formas de predição de disponibilidade usadas, análise de solo ou de folha e/ ou pecíolo, indicam carência de nutrientes.

Como o estado nutricional da planta se reflete na produção e na composição dos frutos, o nitrogênio $(\mathrm{N})$ deve ser usado em doses que não permitam influenciar negativamente os componentes de produção, como na massa de cachos, no seu comprimento e na largura, no seu número de bagas e na massa de 100 bagas (GOLDSPINK \& GORDON, 1991; BELL \& ROBSON, 1999; BRUNETTO, 2008a), já que produções elevadas podem prejudicar a composição da uva e do seu mosto, alterando os teores de sólidos solúveis totais, o pH, a acidez total, os ácidos orgânicos, como os ácidos tartárico e málico, os polifenóis totais, as antocianinas e o teor de nutrientes, como N, fósforo (P), potássio (K), cálcio (Ca) e magnésio $(\mathrm{Mg})$, que devem ser equilibrados e proporcionais na baga (OUGH et al., 1968; SMART, 1991; SPAYD et al., 1994; SPAYD et al., 1995; KELLER \& HRAZDINA, 1998; KELLER et al., 1999; BRUNETTO et al., 2007; BRUNETTO et al., 2008b). Porém, isso é pouco considerado na predição da adubação nitrogenada, por causa da carência de informações nas regiões vitivinícolas do Sul do Brasil.

No Rio Grande do Sul, a Comissão de Química e Fertilidade do Solo do Núcleo Regional Sul da Sociedade Brasileira de Ciência do Solo (CQFS-RS/ SC, 2004) indica a dose de N para a cultura da videira a partir do seu teor total na folha inteira ou no pecíolo e na expectativa de produtividade. Quando diagnosticada a necessidade de aplicação, recomenda o seu parcelamento durante o ciclo vegetativo e produtivo das plantas, sem considerar a composição química da uva produzida. Como a predição da adubação é dependente dos atributos de solo e das condições de clima, que também determinam a tipicidade do vinho, torna-se necessária a realização de experimentos de campo para tentar racionalizar a adubação nitrogenada. Nesse sentido, o presente trabalho teve como objetivo avaliar o efeito da aplicação de $\mathrm{N}$ na produção de uva, em seus componentes e na composição química do seu mosto.

\section{MATERIAL E MÉTODOS}

O trabalho foi realizado na Embrapa Uva e Vinho, localizada no Município de Bento Gonçalves (RS), Brasil (Latitude 2909' 44” S e Longitude 51 $31^{\circ}$ ' 50”W), região da Serra Gaúcha, safra 2004/2005. Aárea experimental foi instalada em vinhedo comercial, plantado em 1986, de viníferas Cabernet Sauvignon enxertadas sob o porta-enxerto $\mathrm{SO}_{4}$, na densidade de 2666 plantas por hectare $(1,5 \mathrm{~m} \times 2,5 \mathrm{~m})$, e conduzidas em sistema latada. O solo foi classificado como NEOSSOLO LITÓLICO (EMBRAPA, 2006) e apresentava, na camada de $0-20 \mathrm{~cm}$, os seguintes atributos: areia $280 \mathrm{~g} \mathrm{~kg}^{-1}$; silte $558 \mathrm{~g} \mathrm{~kg}^{-1}$; argila $162 \mathrm{~g}$ $\mathrm{kg}^{-1}$; matéria orgânica $30,7 \mathrm{~g} \mathrm{~kg}^{-1}$; $\mathrm{pH}$ em água 6,46 ; Índice SMP 6,97; Ca trocável 7,57 $\mathrm{cmol} \mathrm{dm}^{-3}(\mathrm{KCl} 1 \mathrm{~mol}$ $\left.\mathrm{L}^{-1}\right)$; $\mathrm{Mg}$ trocável 3,78cmol $\mathrm{dm}^{-3}\left(\mathrm{KCl}^{\mathrm{c}} 1 \mathrm{~mol} \mathrm{~L}^{-1}\right)$; $\mathrm{P}$ disponível 81 $\mathrm{mg} \mathrm{dm}^{-3}$ (Mehlich 1) e K disponível 87mg $\mathrm{dm}^{-3}$ (Mehlich 1). Os dados climáticos durante a condução do experimento são apresentados na tabela 1 .

O delineamento experimental usado foi o de blocos casualizados, com três repetições, e cada parcela foi formada por quatro plantas com número igual de ramos produtivos, distribuídas ao longo da fila de plantio. Os tratamentos consistiram na aplicação de zero, 15, 30, 45 e $60 \mathrm{~kg} \mathrm{ha}^{-1}$ de $\mathrm{N}$ aplicados de forma parcelada: 50\% no início da brotação (09/09/04); 25\% na brotação (07/10/04) e 25\% na floração (06/11/04). No momento da aplicação do N, as plantas espontâneas

Tabela 1 - Precipitação pluviométrica, temperatura do ar média mensal e insolação no vinhedo das videiras Cabernet Sauvignon submetidas à aplicação de nitrogênio no solo.

\begin{tabular}{lccc}
\hline Ano - mês & $\begin{array}{c}\text { Precipitação } \\
\text { pluviométrica }\end{array}$ & $\begin{array}{c}\text { Temperatura do } \\
\text { ar média mensal }\end{array}$ & Insolação \\
\hline -------mm------- & -------- ${ }^{\circ}$ C-------- & ---horas--- \\
2004 & & & \\
Setembro & 167,6 & 17,2 & 145,2 \\
Outubro & 164,7 & 16,6 & 245,8 \\
Novembro & 144,4 & 18,4 & 207,6 \\
Dezembro & 53,6 & 20,5 & 249,9 \\
2005 & & & 23,1 \\
Janeiro & 51,9 & 22,1 & 221,7 \\
Fevereiro & 54,5 & & \\
\hline
\end{tabular}

Ciência Rural, v.39, n.7, out, 2009. 
foram eliminadas numa área de $0,25 \mathrm{~m}^{2}(0,50 \times 0,50 \mathrm{~m})$, sendo o caule da videira o centro da área. Em seguida, a uréia foi aplicada sobre a superfície do solo e incorporada manualmente, e o vinhedo foi irrigado para diminuir as perdas de $\mathrm{N}$ por volatilização. No decorrer do experimento, a área de $0,25 \mathrm{~m}^{2}$ foi mantida isenta de ervas daninhas para não afetar a disponibilidade de $\mathrm{N}$ às plantas. Durante a condução do experimento, as videiras receberam a aplicação de fertilizantes (exceto N), conforme a recomendação da CQFS-RS/SC (2004), e o manejo do vinhedo foi realizado segundo recomendações técnicas regionais, com aplicação de fungicidas, inseticidas e realização de três podas verdes.

Na mudança de cor das bagas, foram coletadas folhas completas opostas ao primeiro cacho do ramo do ano, como estabelecido pela CQFS-RS/SC (2004) e secas em estufa com circulação de ar a $65^{\circ} \mathrm{C}$ até atingirem massa constante. Posteriormente, as amostras foram moídas e preparadas para a análise de $\mathrm{N}$ total, de acordo com metodologia proposta por TEDESCO et al. (1995). Na maturação da uva, foram coletados aleatoriamente quatro cachos no centro da planta e quatro na parte externa, os quais foram pesados e determinados o comprimento e a largura. Em seguida, foi contado o número de bagas em cada cacho, e foram coletadas bagas no topo do cacho e na parte média e inferior, pesadas, separadas em duas partes, armazenadas e refrigeradas. Depois, os cachos restantes foram colhidos e pesados. Posteriormente, parte das bagas de uva armazenada e refrigerada foi amassada, e foram determinados os sólidos solúveis totais no mosto, com refratômetro digital de bancada com controle de temperatura; o pH foi quantificado com potenciômetro digital; a acidez total por titulação foi determinada com $\mathrm{NaOH}$ 0,1M; o ácido tartárico e o ácido málico foram determinados por cromatografia líquida de alta eficiência (AUGUSTE, 1979); os polifenóis totais (I 280) foram determinados em espectrofotômetro UV/VIS, a 280nm; as antocianinas foram determinadas pelo método de diferença de $\mathrm{pH}$ (RIBÉREAU-GAYON \& STONESTREET, 1965); e o nitrogênio amoniacal foi avaliado por destilação e titulação (TEDESCO et al., 1995). As bagas de uva da outra parte das amostras foram trituradas, e foram determinados os teores totais de N, P, K, Ca e Mg, segundo metodologia proposta por TEDESCO et al. (1995).

Os resultados obtidos foram submetidos à análise de variância e, quando os efeitos foram significativos, foram ajustadas equações de regressão, testando-se o modelo linear e quadrático pelo teste $\mathrm{F}$, escolhendo-se aquele com probabilidade de erro menor que $5 \%(\mathrm{P}<0,05)$.

\section{RESULTADOS E DISCUSSÃO}

A aplicação de doses de $\mathrm{N}$ em viníferas Cabernet Sauvignon aumentou de forma quadrática a produção de uva por planta e por hectare, por causa do aumento da massa dos cachos, causada pelo aumento do comprimento e da largura dos cachos, ou aumento do número de bagas, já que não houve aumento da massa de 100 bagas Em solos com textura arenosa e baixos teores de matéria orgânica, os resultados são positivos, por causa da baixa disponibilidade natural de N (AHMEDULLAH \& ROBERTS, 1991; GOLDSPINK \& GORDON, 1991; BELL \& ROBSON, 1999). Entretanto, convém destacar que os maiores valores dos parâmetros avaliados foram obtidos nas doses de 15 e $30 \mathrm{~kg} \mathrm{ha}^{-1}$ de N. Com isso, pode-se inferir que, nas condições de solo com teores médios de matéria orgânica (CQFS-RS/SC, 2004) e clima com boa distribuição de chuvas durante o ciclo vegetativo e produtivo, doses altas de $\mathrm{N}$ não proporcionam aumento na produção de uvas. Aplicações de 30 até $60 \mathrm{~kg} \mathrm{ha}^{-1}$ de $\mathrm{N}$ promoveram acentuada queda na produção, bem como no número de cachos, no número de bagas por cacho e no comprimento e na largura dos cachos (Tabela 2). Isso pode ter ocorrido porque, quando o $\mathrm{N}$ é usado em doses acima da demanda, promove o crescimento vegetativo, aumentando a incidência de doenças fúngicas e reduzindo as flores fecundas (DUCHÊNE et al., 2001), com isso, a produção de uva diminui.

A aplicação de $\mathrm{N}$ aumentou linearmente $\mathrm{o}$ teor de $\mathrm{N}$ nas folhas completas (Figura 1), mas com baixo coeficiente angular, sendo de $17,1 \mathrm{~g} \mathrm{~kg}^{-1}$ de $\mathrm{N}$ no tratamento testemunha e $18,50 \mathrm{~g} \mathrm{~kg}^{-1}$ na maior dose de $\mathrm{N}\left(60 \mathrm{~kg} \mathrm{ha}^{-1}\right)$. O aumento do teor de $\mathrm{N}$ na folha completa também foi encontrado por BRUNETTO et al. (2008b) em videiras submetidas à aplicação de $\mathrm{N}$, quando cultivadas em um Cambissolo com $11 \mathrm{~g} \mathrm{~kg}^{-1}$ de matéria orgânica, na região do Planalto do RS. Os dados obtidos permitem inferir que, mesmo em um solo com $30,7 \mathrm{~g} \mathrm{~kg}^{-1}$ de matéria orgânica, onde há liberação de satisfatórias quantidades de $\mathrm{N}$ mineral pelo processo de mineralização, o $\mathrm{N}$ do fertilizante aplicado é absorvido e acumulado nas folhas, como observado por BRUNETTO (2008a), usando uréia marcada com ${ }^{15} \mathrm{~N}$ em videiras Cabernet Sauvignon cultivadas no mesmo solo do presente experimento. Isso ocorre porque as folhas seriam o dreno de $\mathrm{N}$ durante o ciclo vegetativo e produtivo da videira por causa do aumento da sua área foliar (BRUNETTO et al., 2006b), e o N não utilizado fisiologicamente pode ser redistribuído e armazenado nas partes perenes para uso no ciclo seguinte.

Os resultados de composição química do mosto de uvas mostram que a aplicação de doses de $\mathrm{N}$ 
Tabela 2 - Produção de uva e componentes de rendimento da cultivar ‘Cabernet Sauvignon’ submetida à aplicação de nitrogênio no solo.

\begin{tabular}{|c|c|c|c|c|c|c|c|}
\hline \multirow{2}{*}{ Variável } & \multicolumn{5}{|c|}{ 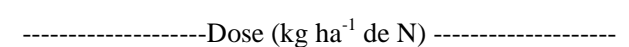 } & \multirow{2}{*}{ Equação } & \multirow{2}{*}{$r^{2}$} \\
\hline & 0 & 15 & 30 & 45 & 60 & & \\
\hline \multicolumn{8}{|l|}{ Produção } \\
\hline Planta (kg) & 1,03 & 1,88 & 1,43 & 1,47 & 0,66 & $y=1,127+0,0461 x-0,00089 x^{2}$ & $0,68^{*}$ \\
\hline Hectare (kg) & 2.766 & 5.032 & 3.819 & 3.920 & 1.752 & $y=3006,700+122,9500 x-2,39810 x^{2}$ & $0,81^{*}$ \\
\hline \multicolumn{8}{|l|}{ Cacho } \\
\hline Número & 20 & 35 & 19 & 18 & 7 & $y=23,421+0,4333 x-0,01206 x^{2}$ & $0,81^{*}$ \\
\hline Massa (g) & 52,94 & 52,93 & 76,70 & 88,64 & 93,84 & $\mathrm{y}=49,505+0,7834 \mathrm{x}$ & $0,39^{*}$ \\
\hline Número de bagas & 95 & 139 & 117 & 124 & 88 & $y=55,674+53,549 x-9,3950 x^{2}$ & $0,74^{*}$ \\
\hline Comprimento (cm) & 14,27 & 16,18 & 15,62 & 15,44 & 13,33 & $y=11,924+3,0209 x-0,54710 x^{2}$ & $0,92 *$ \\
\hline Largura $(\mathrm{cm})$ & 5,52 & 6,83 & 6,22 & 6,12 & 5,25 & $y=4,438+1,5250 x-0,27500 x^{2}$ & $0,78^{*}$ \\
\hline Massa de 100 bagas $^{\mathrm{ns}}$ & 118,49 & 110,92 & 105,74 & 109,64 & 118,36 & & \\
\hline
\end{tabular}

ns = não significativo; *Significativo a $5 \%$ de probabilidade.

aumentou de forma linear os valores de sólidos solúveis totais (SST), polifenóis totais e pH (Tabela 3). O aumento dos valores de SST corresponde a maiores quantidades de açucares, uma vez que, em escala de graus ${ }^{\circ}$ Brix, representa, aproximadamente, 90\% dos açúcares encontrados no mosto. Já maiores valores de polifenóis totais, encontrados em maior quantidade na casca da baga, representam mostos com maior intensidade de cor, tonalidade e melhores características gustativas da uva e, consequentemente, do vinho (WINKLER et al., 1974). Com o aumento dos valores de $\mathrm{pH}$, espera-se que o mosto seja mais sujeito à ação de enzimas

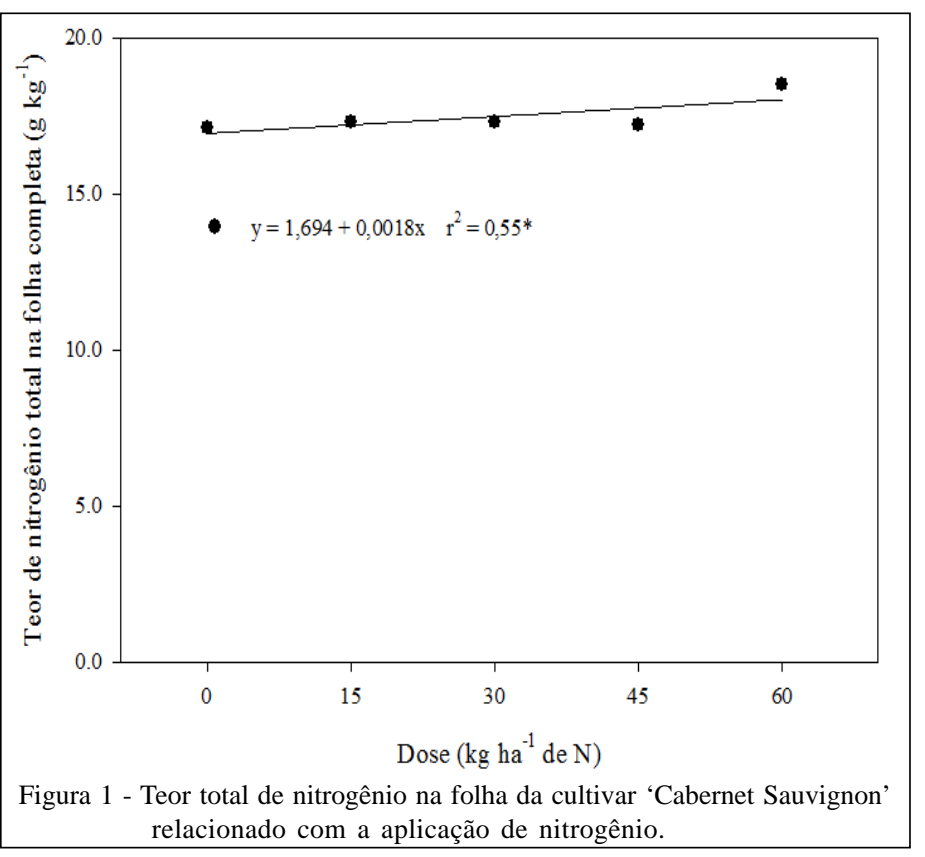

oxidativas durante a fase de pré-fermentação e, caso persistam no vinho, este se torna mais suscetível à oxidação (AERNY, 1985), depreciando a sua qualidade. A aplicação de doses do fertilizante nitrogenado aumentou de forma quadrática os valores de $\mathrm{N}$ amoniacal no mosto (Tabela 3), o que seria de se esperar, já que há relatos de situações similares como os de OUGH et al. (1968), SPAYD et al. (1994) e SPAYD et al. (1995), nos Estados Unidos, e BRUNETTO et al. (2007), na região da Campanha do RS. Convém ressaltar que, primeiro, esses resultados corroboram com o aumento do teor de $\mathrm{N}$ total nas folhas (Figura 1), o que pode ser uma indicação dos parâmetros qualitativos ou da provável tipificação do mosto e/ou do vinho. Segundo, nas bagas de uva, é possível destacar que o teor do $\mathrm{N}$ amoniacal, que junto com outras formas de $\mathrm{N}$, como os aminoácidos, possuem correlação positiva com o crescimento de microrganismos no mosto da uva (MONTEIRO \& BISSON, 1991; JIRANEK et al., 1995), diminuindo as paradas de fermentação durante a elaboração do vinho.

Os valores de acidez total e de ácidos tartárico e málico, que são responsáveis pela estabilidade do vinho, diminuíram de forma linear com o aumento da dose de N (Tabela 3), como observado por KELLER et al. (1999). O aumento de doses de $\mathrm{N}$ também diminuiu de forma linear os valores de antocianinas no mosto, provocando a diminuição da 
Tabela 3 - Composição química do mosto e teores totais de nitrogênio, fósforo, potássio, cálcio e magnésio na baga da uva da cultivar ‘Cabernet Sauvignon’ submetida à aplicação de nitrogênio no solo.

\begin{tabular}{|c|c|c|c|c|c|c|c|}
\hline \multirow{2}{*}{ Variável } & \multicolumn{5}{|c|}{ 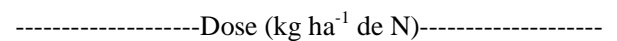 } & \multirow{2}{*}{ Equação } & \multirow{2}{*}{$r^{2}$} \\
\hline & 0 & 15 & 30 & 45 & 60 & & \\
\hline \multicolumn{8}{|c|}{ 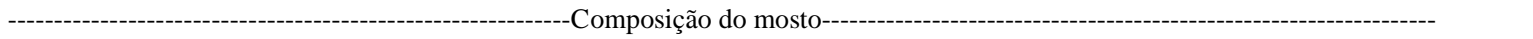 } \\
\hline SST ( ${ }^{\circ}$ Brix) & 14,82 & 15,00 & 16,00 & 16,50 & 15,97 & $y=14,900+0,0253 x$ & $0,46^{*}$ \\
\hline $\mathrm{pH}$ & 3,17 & 3,46 & 3,49 & 3,64 & 3,58 & $y=3,271+0,0066 x$ & $0,70 *$ \\
\hline Acidez total (meq L $\left.{ }^{-1}\right)$ & 75,00 & 62,00 & 57,00 & 54,00 & 52,50 & $y=70,700-0,3535 x$ & $0,77^{*}$ \\
\hline Ácido Tartárico ( $\left.\mathrm{g} \mathrm{L}^{-1}\right)$ & 3,77 & 3,54 & 2,98 & 2,76 & 2,54 & $y=3,773-0,0216 x$ & $0,86 *$ \\
\hline Ácido Málico (g L $\left.{ }^{-1}\right)$ & 3,88 & 3,50 & 2,50 & 2,42 & 2,34 & $y=3,762-0,0276 x$ & $0,84^{*}$ \\
\hline Polifenóis totais (I 280) & 14,85 & 14,05 & 15,62 & 18,32 & 18,57 & $y=13,940+0,0781 x$ & $0,65^{*}$ \\
\hline Antocianinas $\left(\mathrm{mg} \mathrm{L}^{-1}\right)$ & 115,17 & 83,02 & 94,15 & 103,02 & 102,25 & $\begin{array}{l}y=109,337-1,1913 x+ \\
0,01920 x^{2}\end{array}$ & $0,38^{*}$ \\
\hline Nitrogênio amoniacal $\left(\mathrm{mg} \mathrm{L}^{-1}\right)$ & 4,50 & 11,00 & 9,44 & 4,51 & 4,20 & $\begin{array}{l}\mathrm{y}=5,721+0,2761 \mathrm{x}- \\
0,00539 \mathrm{x}^{2}\end{array}$ & $0,57^{*}$ \\
\hline Nitrogênions (\%) & 0,46 & $\begin{array}{l}---T e o \\
0,48\end{array}$ & $\begin{array}{c}\text { totais } n \\
0,47\end{array}$ & $\begin{array}{c}\text { ga da uv } \\
0,43\end{array}$ & - & --------------------------------------------- & \\
\hline Fósforo $^{\mathrm{ns}}(\%)$ & 0,05 & 0,05 & 0,05 & 0,05 & 0,05 & & \\
\hline Potássio (\%) & 0,32 & 0,38 & 0,34 & 0,36 & 0,40 & $y=0,334+0,0009 x$ & $0,21^{*}$ \\
\hline Cálcio $^{\text {ns }}(\%)$ & 0,02 & 0,02 & 0,02 & 0,02 & 0,02 & & \\
\hline Magnésio $^{\mathrm{ns}}(\%)$ & 0,01 & 0,01 & 0,01 & 0,01 & 0,01 & & \\
\hline
\end{tabular}

ns = não significativo; *Significativo a $5 \%$ de probabilidade.

coloração do mosto e do futuro vinho (SMART, 1991; KELLER \& HRAZDINA, 1998; KELLER et al., 1999; BRUNETTO et al., 2007). De acordo com esses autores, isso se deve à distribuição das antocianinas das bagas para as partes em crescimento, como os ramos e as folhas, que têm os seus crescimentos estimulados pela aplicação de N, podendo reduzir a atividade de enzimas que regulam a síntese de antocianinas. Convém relatar que, em geral, os trabalhos que avaliam a interferência do $\mathrm{N}$ na composição da uva não relatam informações sobre o tipo de solo e o seu teor de matéria orgânica onde as videiras foram cultivadas e, com isso, a discussão dos dados é restrita à quantidade de $\mathrm{N}$ aplicada e ao impacto na produção e na composição da uva e/ou do seu mosto. Além disso, nem sempre são conhecidos os valores padrões por cultivar e por região de variáveis de composição química da uva e do seu mosto, dificultando a interpretação e as inferências sobre se os dados obtidos e se são ou não adequados para a elaboração de vinhos. Porém, o problema mais recorrentemente detectado em vinícolas do RS e do Brasil é a parada de fermentação, quando os teores de formas de $\mathrm{N}$, como o amônio, são pequenos, havendo necessidade de adicioná-lo para a retomada.

Os resultados de teores totais de nutrientes na baga mostram que a aplicação de doses de $\mathrm{N}$ não afetou os teores totais de N, P, Ca e Mg (Tabela 3). As doses de $\mathrm{N}$ aumentaram de forma linear a porcentagem de potássio nas bagas, o que deve ser atribuído ao fato de que as plantas submetidas à adição de $\mathrm{N}$ aumentam a área foliar, aumentando a transpiração, forçando o transporte via xilema e a translocação via floema para as partes em crescimento e alcançando as bagas, já que as plantas possuem um eficiente sistema de absorção de potássio e a biodisponibilidade nesses solos é alta. Porém, o aumento do potássio na baga e, consequentemente, no mosto, potencializa a formação de bitartarato de potássio no vinho, elevando os valores de $\mathrm{pH}$ do vinho, acelerando sua oxidação e diminuindo a sua qualidade ao longo do tempo (RIZZON, 1985; MPELASOKA et al., 2003; BRUNETTO et al., 2007).

\section{CONCLUSÕES}

A produção de uva de viníferas Cabernet Sauvignon em solos com teores médios de matéria orgânica é máxima com a aplicação de doses entre 15 e $30 \mathrm{~kg} \mathrm{ha}^{-1}$ de nitrogênio. A aplicação de nitrogênio aumenta os teores de nitrogênio amoniacal e a porcentagem de potássio no mosto, mas altera negativamente o teor de antocianinas, o que interfere na cor dos vinhos tintos e na formação de precipitados. 


\section{AGRADECIMENTOS}

Ao Conselho Nacional de Desenvolvimento Científico e Tecnológico (CNPq), pela bolsa de estudo do primeiro autor durante sua Tese de Doutorado e ao segundo, ao terceiro e ao nono autor pela bolsa de Produtividade em Pesquisa. À Coordenação de Aperfeiçoamento de Pessoal de Nível Superior (Capes), pela bolsa de Pós-doutorado ao primeiro autor. À Embrapa Uva e Vinho por disponibilizar os vinhedos para a instalação do experimento e pelo financiamento parcial do trabalho. Aos funcionários do Laboratório de Análise de Solo e Tecido e de Enoquímica da Embrapa Uva e Vinho pelo auxílio nas análises laboratoriais.

\section{REFERÊNCIAS}

AERNY, J. Définition de La qualité de La vendenge. Revue Suisse de Viticulture, Arboriculture, horticulture, Nyon, v.17, p.219-223, 1985.

AGEHARA, S.; WARNCKE, D.D. Soil moisture and temperature effects on nitrogen release from organic nitrogen sources. Soil Science Society American Journal, Madison, v.69, p.18441855, 2005.

AHMEDULLAH, M.; ROBERTS, S. Effect of soil-applied nitrogen on the yield and quality of Concord grapevines. In: INTERNATIONAL SYMPOSIUM ON NITROGEN IN GRAPES AND WINE, 1991, Washington. Proceeding... Washington: Seattle: The American Society for Enology and Viticulture, 1991. p.200-201.

AUGUSTE, M. H. Application de la chomatographie en phase liquide à haute pression à l'analyse des moûts et des vins. 1979. 135f. Tese (Doutorado em Enologia Ampelologia) - Université de Bordeaux II.

BELL, S. J.; ROBSON, A. Effect of nitrogen fertilization on growth, canopy density, and yield of Vitis viniferas L. cV. 'Cabernet Sauvignon'. American Journal of Enology and Viticulture, Davis, v.50, p.351-358, 1999.

BRUNETTO, G. Absorção e redistribuição do nitrogênio aplicado em plantas de videira. 2004. 74f. Dissertação (Mestrado em Ciência do Solo) - Universidade Federal de Santa Maria.

BRUNETTO, G. et al. Recuperação e distribuição do nitrogênio fornecido a videiras jovens. Pesquisa Agropecuária Brasileira, Brasília, v.41, n.8, p.1299-1304, 2006a. Disponível em: <http:// www.scielo.br/scielo.php?script $=$ sci_arttext \&pid $=$ S0100204X2006000800013\&lng=pt\&nrm=iso $>$. Acesso em: 20 maio 2009. doi: 10.1590/S0100-204X2006000800013.

BRUNETTO, G. et al. Destino do nitrogênio em videiras 'Chardonnay' e 'Riesilng Renano' quando aplicado no inchamento das gemas. Revista Brasileira de Fruticultura, Jaboticabal, v.28, p.497-500, 2006b. Disponível em: <http:// www.scielo.br/scielo.php?script=sci_arttext\&pid=S0100$29452006000300034 \& \operatorname{lng}=p t \& n r m=i s o>$. Acesso em: 20 maio 2009. doi: 10.1590/S0100-29452006000300034.

BRUNETTO, G. et al. Aplicação de nitrogênio em videiras na Campanha Gaúcha: Produtividade e características químicas do mosto da uva. Ciência Rural, Santa Maria, v.37, n.2, p.389393, 2007. Disponível em: <http://www.scielo.br/ scielo.php? script=sci_art text \& pid=S 0103 84782007000200014\&lng=pt\&nrm=iso $>$. Acesso em: 20 maio 2009. doi: 10.1590/S0103-84782007000200014.

BRUNETTO, G. Nitrogênio em videira: Recuperação, acumulação e alterações na produtividade e na composição da uva. 2008a. 139f. Tese (Doutorado em Ciência do Solo) - Universidade Federal de Santa Maria.

BRUNETTO, G. et al. Produção, composição da uva e teores de nitrogênio na folha e no pecíolo em videiras submetidas à adubação nitrogenada. Ciência Rural, Santa Maria, v.38, n.9, p.2622-2625, 2008b. Disponível em: <http://www.scielo.br/ scielo.php? script=s ci_art text \& pid=S 0103 84782008000900035\&lng=pt\&nrm=iso>. Acesso em: 20 maio 2009. doi: 10.1590/S0103-84782008005000026.

COMISSÃO DE QUÍMICA E FERTILIDADE DO SOLO - RS/ SC. Manual de adubação e calagem para os Estados do Rio Grande do Sul e de Santa Catarina. 10.ed. Porto Alegre: SBCS - Núcleo Regional Sul/UFRGS, 2004. 400p.

DAL BÓ, M.A. Efeito da adubação NPK na produção, qualidade da uva e nos teores foliares de nutrientes da videira. Revista Brasileira de Fruticultura, Cruz das Almas, v.14, p.189194, 1992.

DELAS, J. et al. Effects of nitrogen fertilization and grafting on the yield and quality of the crop of Vitis vinifera cv. 'Merlot'. In: INTERNATIONAL SYMPOSIUM ON NITROGEN IN GRAPES AND WINE, 1991, Washington. Proceeding... Washington: Seattle: The American Society for Enology and Viticulture, 1991. p.242-248.

DUCHÊNE, E. et al. Effects of nitrogen nutrition timing on fruit set of grapevine cv. 'Grenache'. Vitis, Landau, v.40, p.45-46, 2001.

EMBRAPA-CNPS. Sistema brasileiro de classificação de solos. 2.ed. Rio de Janeiro, 2006. 306p.

GOLDSPINK, B.; GORDON, C. Response of Vitis vinifera cv. Sauvignon blanc grapevines to timed applications of nitrogen fertilizers. In: INTERNATIONAL SYMPOSIUM ON NITROGEN IN GRAPES AND WINE, 1991, Washington. Proceeding... Washington: Seattle: The American Society for Enology and Viticulture, 1991. p.255-258.

JIRANEK, V. et al. Amino acid and ammonium utilization by saccharomyces cerevisiae wine yeasts from a chemically defined medium. American Journal of Enology and Viticulture, Davis, v.46, p.75-81, 1995.

KELLER, M; HRAZDINA, G. Interaction of nitrogen availability during bloom and light intensity during veraison. II. Effects on anthocyanin and phenolic development during grape ripening. American Journal of Enology and Viticulture, Davis, v.49, p.341-349, 1998.

KELLER, M. et al. Excessive nitrogen supply and shoot trimming can impair colour development in Pinot Noir grapes and wine. Australian Journal of Grape and Wine Research, Adelaide, v.5, p.45-55, 1999.

MONTEIRO, F. F.; BISSON, L. F. Biological assay of nitrogen content of grape juice and prediction of sluggish fermentations. 
American Journal of Enology and Viticulture, Davis, v.42, p.47-57, 1991.

MPELASOKA, B. S. et al. A review of potassium nutrition in grapevines with special emphasis on berry accumulation. Australian Journal of Grape and Wine Research, Adelaide, v.9, p.154-168, 2003.

OUGH, C. S. et al. Rootstock-scion interactions concerning winemaking. I. Juice composition changes and effects on fermentation rate with St George and 99-R rootstocks at two nitrogen fertilizer levels. American Journal of Enology and Viticulture, Davis, v.19, p.213-227, 1968.

RIBÉREAU-GAYON, P.; STONESTREET, E. Le dosage des anthocyanes dans les vins rouges. Bulletin de la Societé Chimique de France, Paris, v.9, n.419, p.2649-2652, 1965.

RIZZON, L. A. Incidence de La macération sur La composition chimbique dês vins. 1985. 225f. Tese (Doutorado em Enologia - Ampelologia) - Université de Bordeaux II.

SMART, R. E. Canopy microclimate implications for nitrogen effects on yield and quality. In: INTERNATIONAL
SYMPOSIUM ON NITROGEN IN GRAPES AND WINE, 1991, Washington. Proceeding... Washington: Seattle: The American Society for Enology and Viticulture, 1991. p.90101.

SPAYD, S.E. et al. Nitrogen fertilization of white Riesling grapes in Washington. Must and wine composition. American Journal of Enology and Viticulture, Davis, v.45, p.34-42, 1994.

SPAYD, S.E. et al. Yeast growth in Riesling juice as affected by vineyard nitrogen fertilization. American Journal of Enology and Viticulture, Davis, v.46, p.49-55, 1995.

TEDESCO, M.J. et al. Análise de solo, plantas e outros materiais. Porto Alegre: UFRGS/FA/DS, 1995. 174p.

TRINSOUTROT, I. et al. Biochemical quality of crop residues and carbon and nitrogen mineralization kinetics under nonlimiting nitrogen conditions. Soil Science Society American Journal, Madison, v.64, p.918-926, 2000.

WINKLER, A.J. et al. General viticulture. Berkeley: University California, 1974. 710p. 